Supporting Information:

\title{
Pre-doped oxygenated defects activate nitrogen-doped graphene for the oxygen reduction reaction
}

Lin Jiang ${ }^{1}$, Bas van Dijk ${ }^{1}$, Longfei $\mathrm{Wu}^{2}$, Clement Maheu ${ }^{3}$, Jan P. Hofmann²,3, Viorica Tudor ${ }^{1}$, Marc T.

M. Koper ${ }^{1}$, Dennis G. H. Hetterscheid ${ }^{1 *}$, Grégory F. Schneider ${ }^{1 *}$

${ }^{1}$ Leiden Institute of Chemistry, Leiden University, Leiden, The Netherlands

${ }^{2}$ Laboratory for Inorganic Materials and Catalysis, Department of Chemical Engineering and Chemistry, Eindhoven University of Technology, Eindhoven, The Netherlands

${ }^{3}$ Surface Science Laboratory, Department of Materials and Earth Sciences, Technical University of Darmstadt, 64287 Darmstadt, Germany

* to whom correspondence should be addressed:

Schneider, G.F., g.f.schneider@,chem.leidenuniv.nl,

Hetterscheid, D.G.H., d.g.h.hetterscheid@chem.leidenuniv.nl 


\section{Methods}

1.1 Materials. Chemical vapor deposition (CVD) graphene is grown on a polycrystalline copper foil (Alfa Aesar, 99.999\% purity, $25 \mu \mathrm{m}$ thickness) in a commercially available hot-wall chamber (planarGROW-2B, planarTECH). After annealing and stabilizing the copper foil at $1035{ }^{\circ} \mathrm{C}$ in an atmosphere of $\mathrm{H}_{2}$ (g, 40 mTorr), graphene was grown at the surface of copper by introducing $35 \mathrm{sccm}$ $\mathrm{CH}_{4}$ (g, 500mTorr) for a desired period. Epoxy resin (including the curing agent) was supplied by GENTEC. Poly(methyl methacrylate) (Sigma Aldrich) was used for CVD graphene transfer. Potassium chloride $(\mathrm{KCl}, \geq 99.0 \%)$, potassium ferricyanide $\left(\mathrm{K}_{3}\left[\mathrm{Fe}(\mathrm{CN})_{6}\right], \geq 99.0 \%\right)$ and ammonia persulfate $\left(\left(\mathrm{NH}_{4}\right)_{2} \mathrm{~S}_{2} \mathrm{O}_{8}, \geq 98.0 \%\right)$ were supplied by Sigma Aldrich. Sulfuric acid $\left(98 \% \mathrm{H}_{2} \mathrm{SO}_{4}, \geq 99.999 \%\right)$ and sodium hydroxide monohydrate $\left(\mathrm{NaOH} \cdot \mathrm{H}_{2} \mathrm{O}\right.$, TraceSelect $\left.\geq 99.9995 \%\right)$ were purchased from Honeywell Fluka. Potassium perchlorate $\left(\mathrm{NaClO}_{4}, \mathrm{EMSURE}{ }^{\circledR}\right)$ was ordered from Merck. The electrolyte solution was prepared with ultrapure water (Millipore Milli-Q gradient A10 system, 18.2 $\mathrm{M} \Omega . \mathrm{cm})$. All gases were supplied by Linde Gas (5.0).

1.2 Plasma condition. A capacitively coupled plasma system with a radio-frequency (RF) of $40 \mathrm{kHz}$ and $200 \mathrm{~W}$ power from Diener electronic was employed at room temperature. The base pressure of this system is less than 0.02 mbar. To achieve mild plasma conditions, a Faraday cage equipped with grid was employed to shield all the energetic ions, thus forming a mild radical plasma to treat the graphene samples inside the cage. The parameters used for nitrogenation treatments were $16 \mathrm{~W}$ power and 0.8 mbar pressure for ammonia plasma. Oxygen and argon plasmas were applied with 30W/0.5 mbar and $10 \mathrm{~W} / 0.8$ mbar, respectively.

1.3 Structural characterization. Raman spectra and mapping were collected using a WITEC alpha300 $\mathrm{R}$ - Confocal Raman Imaging with a laser wavelength of $532 \mathrm{~nm}$. A $100 \times$ magnification objective was used to form a laser inspection region of $300 \mu \mathrm{m}$ in diameter. To minimize the potential damage from laser heating effect, the laser power was controlled under $2 \mathrm{~mW}$. All the measurements were performed under ambient conditions at room temperature.

The electric transport measurements of graphene field-effect transistor devices were performed on a SR830 DSP lock-in amplifier with narrow filters. Electrolyte- or electrochemical-gated GFET measurements were carried out in $0.1 \mathrm{M} \mathrm{KCl}$ solution containing $10 \mathrm{mM}$ Tris as the buffer (pH 8). The gate voltage was applied on a $\mathrm{AgCl} / \mathrm{Ag}$ wire as the reference electrode, at a sweep rate of $100 \mathrm{mV} \mathrm{s}^{-1}$, while the source/drain current was fixed at $0.1 \mu \mathrm{A}$.

XPS measurements were performed at a Thermo Fischer Escalab 250 spectrometer. It is equipped with a monochromatic X-ray source $(\mathrm{A} 1 \mathrm{~K} \alpha=1486.6 \mathrm{eV})$ and has a spot size of $650 \mu \mathrm{m}$. Survey spectra were acquired with a pass energy of $50 \mathrm{eV}$, a step size of 0.1 and a dwell time of $50 \mathrm{~ms}$ per measurement point. The detailed scans were acquired with a lower pass energy $(10 \mathrm{eV})$ and a lower step size $(0.05$ 
$\mathrm{eV}$ ). Energy calibration was performed by referring to the $\mathrm{C} 1 \mathrm{~s} \mathrm{sp}{ }^{2}$ peak of highly ordered pyrolytic graphite (HOPG) at $284.6 \mathrm{eV}$ and CasaXPS software was used to analyze and fit the spectra. Considering the probing depth of XPS ( $\sim 3-5 \mathrm{~nm})$, any impurities adsorbing at the surface or trapped at the interface will be detected. Therefore, graphene on copper foil (the air-face) was used to avoid unnecessary transfer induced contaminations. Similar with the samples used for the ORR experiments, graphene for XPS analysis were stored in vacuum environment ( $\sim$ mbar) or inert atmosphere, and used as fresh as possible.

1.4 Electrochemical measurements. The electrochemical experiments were carried out in a custom made one-compartment three-electrode electrochemical cell at ambient conditions. The working electrode is the as-prepared graphene and the counter electrode a graphite rod. All potentials in this work are reported with respect to a reversible hydrogen electrode (RHE) reference electrode, a Pt mesh in $\mathrm{H}_{2}$ saturated electrolyte operating at the same $\mathrm{pH}$ and connected to cell via a Luggin capillary. Autolab PGSTAT 12 potentiostats operated by NOVA software were used for the electrochemical measurements. The measured current was normalized to the geometric surface area of the working electrode and not corrected for ohmic drop as the obtained currents were very low. Prior to the ORR experiments, the cell containing the electrolyte solution was purged and saturated with $\mathrm{O}_{2}$. For capacitive current measurements, argon was purged at least for 30 min to fully remove dissolved $\mathrm{O}_{2}$ in the solution. The cyclic voltammetry $(\mathrm{CV})$ and polarization curves were measured at a scan rate of $100 \mathrm{mV} \mathrm{s}^{-1}$. For each graphene sample, at least $10 \mathrm{CV}$ scans were performed to obtain stable current signals prior to polarization curves.

1.5 Pristine G on epoxy support. The top side of the as-grown CVD graphene on copper foil $(\sim 1.5 \mathrm{~mm}$ $\times 10 \mathrm{~mm}$ ) was glued to the epoxy resin layer (homogeneously mixed with the curing agent) sitting on a glass slide. After the epoxy resin was cured at room temperature for 24 hours, graphene had grown in the backside of the copper (now facing to the air) was removed using an oxygen plasma $(100 \mathrm{~W} / 0.5$ mbar/2 min). After protecting the copper end with a clean and hydrophobic film of cellulose acetate butyrate $(\mathrm{CAB})$, ammonia persulfate solution $(0.5 \mathrm{M})$ was used to etch the non-protected copper and to expose the underlying graphene, referred to as pure graphene. Then the graphene was wired out (using silver epoxy) via the retained copper foil with a low contact resistance. For the fabrication of graphene field effect transistor devices, similar procedures were adopted except that two ends of the copper foil (a strip of copper) were preserved as source and drain electrodes, respectively.

1.6 G@GC. The glassy carbon (GC) disk electrode $\left(0.196 \mathrm{~cm}^{2}\right)$ and platinum ring were supplied by Pine Instruments and controlled by a Pine MSR rotator in a ChangeDisk configuration. Prior to use, both the disk and ring electrodes were mechanically and separately polished with 1.0, 0.3 and 0.05 micron alumina slurry respectively for $2 \mathrm{~min}$ with subsequent rinsing and sonication in water for $10 \mathrm{~min}$. The separate polishing of ring and disk excluded any potential contamination of platinum onto the GC disk electrode. After polishing and cleaning, poly(methyl methacrylate) (PMMA) was spin-coated onto the CVD graphene on copper 
foil and cured to form a carrier film. After the underlying copper was etched in ammonium persulfate solution, PMMA-graphene layer floating on water (to rinse ammonium salt out) was transferred onto the target substrate. As illustrated in Figure S3, monolayer graphene coated with PMMA layer was denoted as G' and transferred onto the GC disk (G'@GC); G' was transferred onto another monolayer CVD graphene on copper foil to prepare a bilayer graphene film, denoted as G@GC. Finally the transferred graphene was obtained by removing PMMA in acetone. Electrochemical RRDE experiments were carried out in a two-compartment cell with a three-electrode set-up. The counter electrode was separated from the rotating disk electrode via a water permeable glass frit in a different compartment. A capacitor of 10 $\mu \mathrm{F}$ was connected between the RHE and electrolyte solution through a platinum wire to lower the noise ratio especially for the ring current.

\section{Supplementary notes}

\subsection{Electrical doping effect in $\mathrm{N}$-doped graphene}

It is known that the incorporation of $\mathrm{N}$ atoms into the two-dimensional in-plane of graphene can vary in different configurations of pyridinic, quaternary and pyrrolic $\mathrm{N}$, that exert distinct effects on the electronic structures and transport properties of graphene. ${ }^{1}$ Normally pyridinic and pyrrolic N p-dopes graphene while quaternary $\mathrm{N}$ introduces n-type doping in graphene. Of note, a weak n-doping effect can be found in hydrogenated pyridinic and pyrrolic $\mathrm{N}$ wherein the extra charge on $\mathrm{N}$ is forced into the delocalized carbon $\pi$-network. ${ }^{2,3}$ Quaternary $\mathrm{N}$ sites have been reported to act as a positively charged scattering center, which can enhance the electron-hole asymmetry in transport properties. ${ }^{4}$ Given the observed n-doping behavior as well as the symmetric $G\left(V_{\mathrm{g}}\right)$ curves, it is expected that hydrogenated pyridinic and/or pyrrolic $\mathrm{N}$ are the dominant configurations in the $\mathrm{N}$-doped graphene of this study.

\subsection{Working principle of graphene field effect transistor (GFET)}

Using $\mathrm{AgCl} / \mathrm{Ag}$ as the reference electrode, the gate voltage $\left(V_{\mathrm{g}}\right)$ is applied through the electrolyte solution ( $0.1 \mathrm{M} \mathrm{KCl}$ with $10 \mathrm{mM}$ Tris, $\mathrm{pH} \sim 8)$. When $V_{\mathrm{g}}$ sweeps from negative to positive voltages, the dominant charge carriers in graphene correspondingly change from hole to electron as the Fermi level $\left(E_{\mathrm{F}}\right)$ of graphene shifts from the valence band to the conduction band. As a result, the conductance $(G)$ of graphene demonstrate an ambipolar behavior with $V_{\mathrm{g}}$ in Figure 1c (black line). The voltage of the minimum conductance $\left(G_{\min }\right)$ is called charge neutrality point $(\mathrm{CNP})$ with equal concentrations of hole and electron carriers. The positive CNP $(80 \mathrm{mV})$ for untreated graphene suggests a positive doping from the underneath epoxy substrate. 

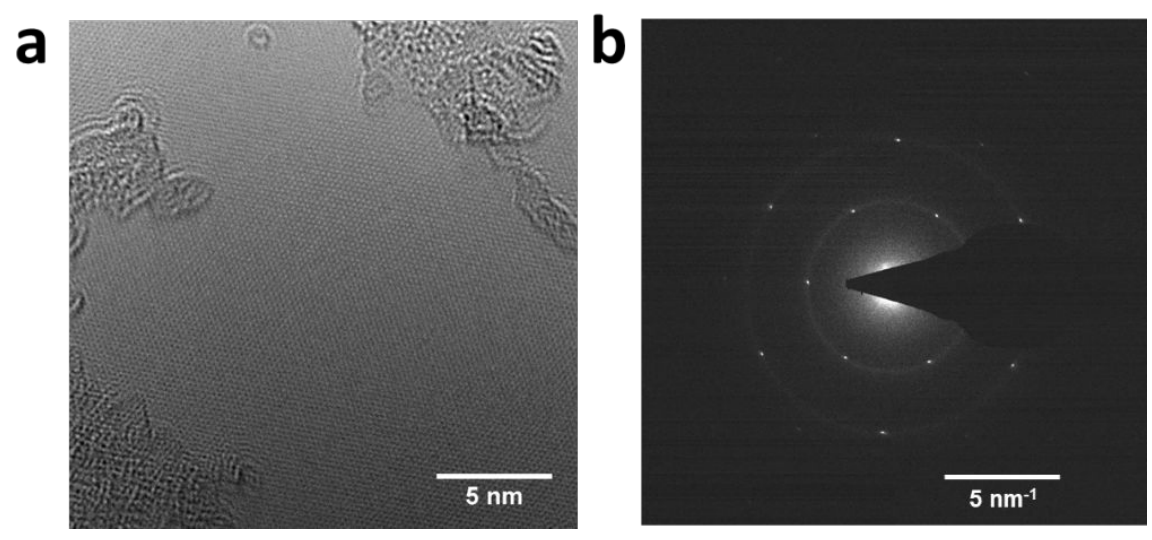

Figure S1. High resolution transmission electron microscopy image of monolayer CVD graphene (a) and the fast Fourier transform pattern (b).
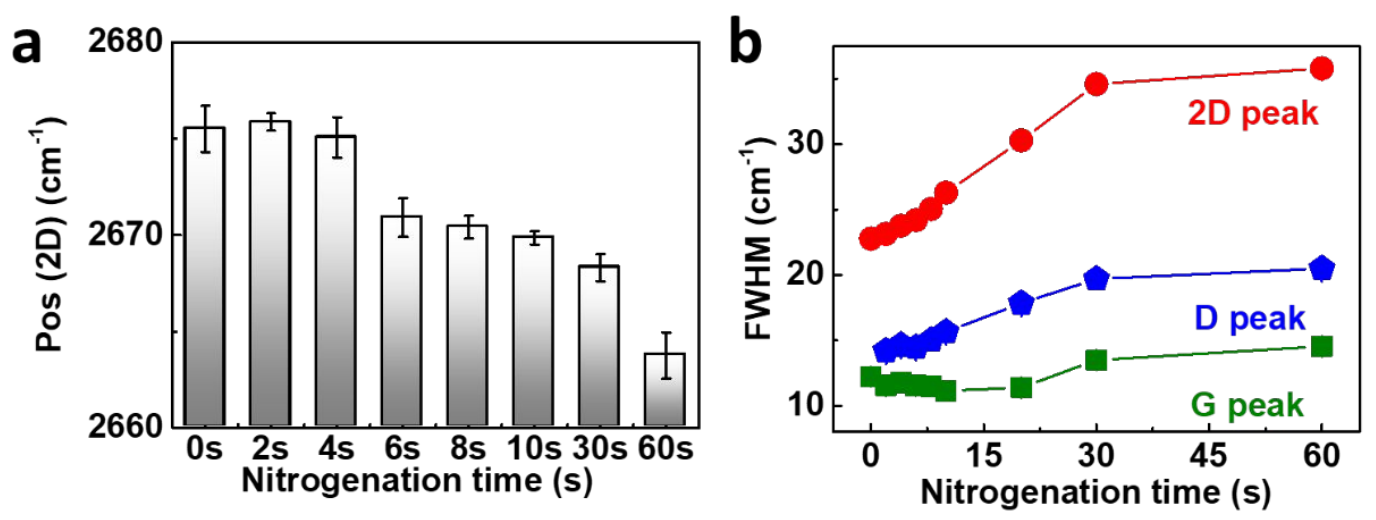

Figure S2. Raman spectroscopy of N-doped monolayer graphene. (a) Red-shift of 2D peak position vs nitrogenation times. (b) Variations of full width at half maximums (FWHMs) for D, G and 2D peaks upon 0 to $60 \mathrm{~s}$ nitrogenation.

Table S1. Defect density $\left(n_{\mathrm{D}}\right)$ and interdefect distance $\left(L_{\mathrm{D}}\right)$ analysis in monolayer graphene based on nitrogenation time

\begin{tabular}{l|ccccccccc}
\hline $\mathrm{NH}_{3}$ time $(\mathrm{s})$ & 0 & 2 & 4 & 6 & 8 & 10 & 20 & 30 & 60 \\
\hline$n_{\mathrm{D}}\left(\times 10^{10} \mathrm{~cm}^{-2}\right)$ & $1 \pm 0.1$ & $3.1 \pm 0.4$ & $10.2 \pm 0.9$ & $17.6 \pm 1.5$ & $21.6 \pm 3.2$ & $23.2 \pm 1.2$ & $3.9 \pm 1.5$ & $4.8 \pm 2.9$ & $5.5 \pm 1.4$ \\
$L_{\mathrm{D}}(\mathrm{nm})$ & $\sim 56.6$ & $\sim 32.0$ & $\sim 17.7$ & $\sim 13.5$ & $\sim 12.2$ & $\sim 11.7$ & $\sim 9.0$ & $\sim 8.1$ & $\sim 7.6$ \\
\hline
\end{tabular}




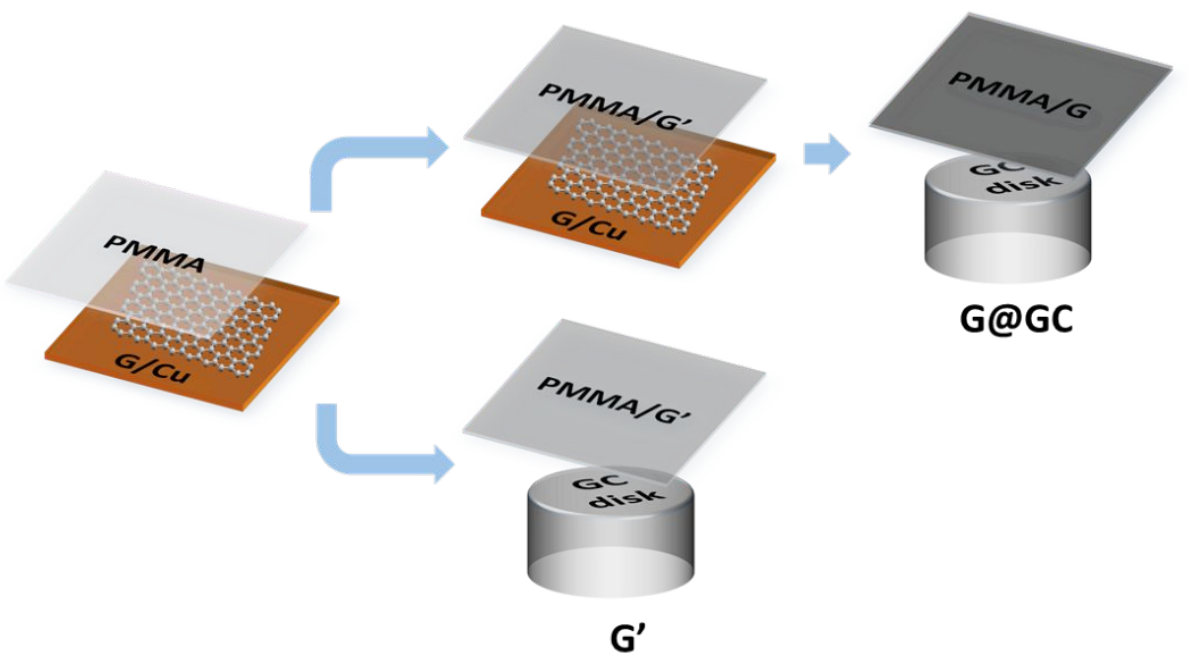

Figure S3. Illustration schemes of graphene surface preparations, namely G@GC and G’@GC for ORR measurements. Monolayer graphene is transferred onto the glassy carbon (GC) disk as $\mathrm{G}^{\prime} @ \mathrm{GC}$ and bilayer graphene surface as $\mathrm{G} @ \mathrm{GC}$. PMMA is poly(methyl methacrylate) polymer typically used for graphene transfer from copper to arbitrary substrates.
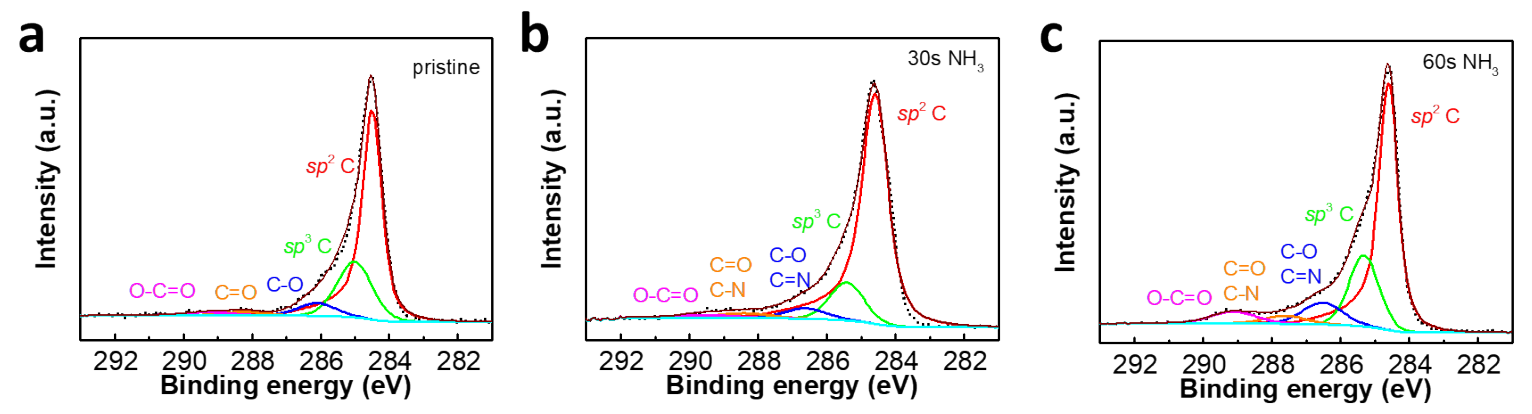

Figure S4. XPS C $1 s$ core level spectra for pristine graphene (a) and $30 \mathrm{~s} \mathrm{(b),} 60 \mathrm{~s} \mathrm{(c)} \mathrm{of} \mathrm{N-doped}$ graphene. 

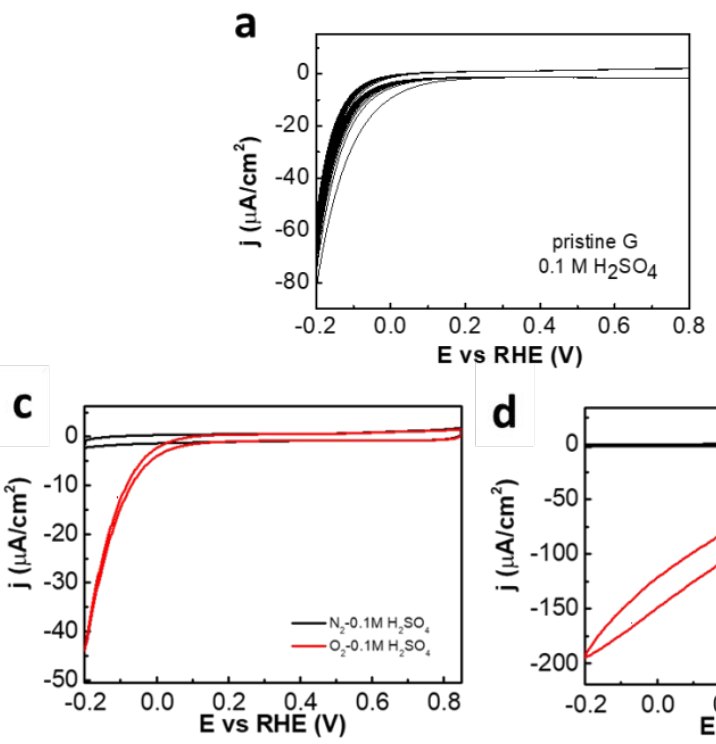
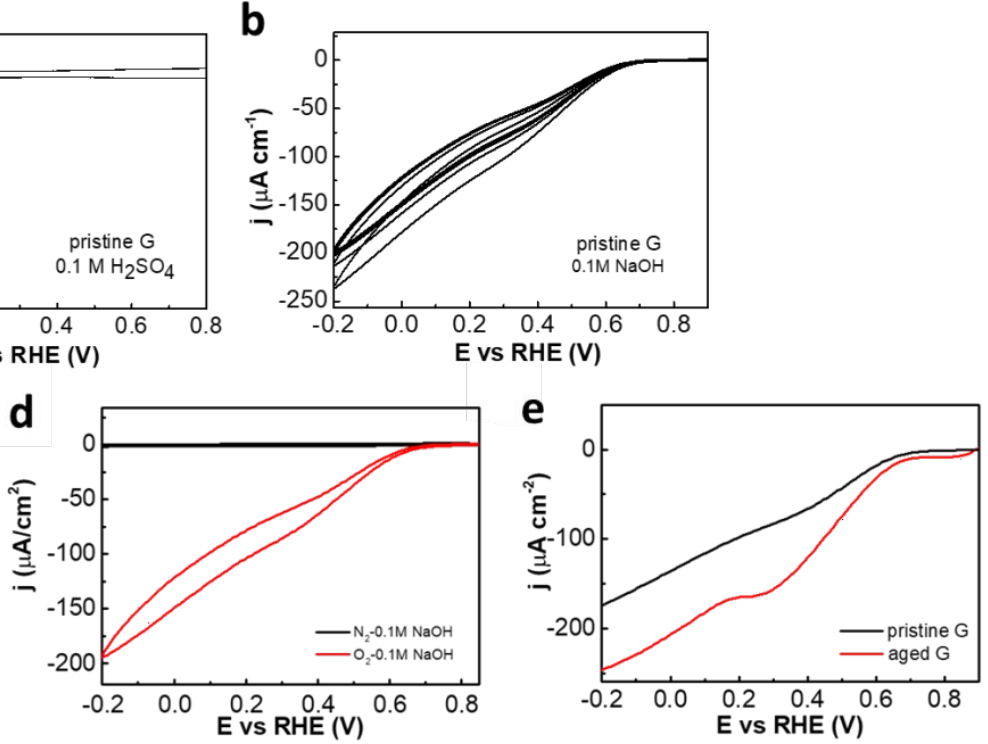

Figure S5. CVs of pristine $\mathrm{G}$ in acid and alkaline media. a) Ten CV scans in $0.1 \mathrm{M} \mathrm{H}_{2} \mathrm{SO}_{4}$ to obtain stable ORR current. b) Ten CV scans in $0.1 \mathrm{M} \mathrm{NaOH}$ to obtain stable ORR current. c) CVs in argon purged and $\mathrm{O}_{2}$ purged $0.1 \mathrm{M} \mathrm{H}_{2} \mathrm{SO}_{4}$ solution. d) CVs in argon purged and $\mathrm{O}_{2}$ purged $0.1 \mathrm{M} \mathrm{NaOH}$ solution. e) LSV curves of an aged $\mathrm{G}$ with an evident peak at $\sim 0.4 \mathrm{~V}$ as compared to Pristine $\mathrm{G}$.
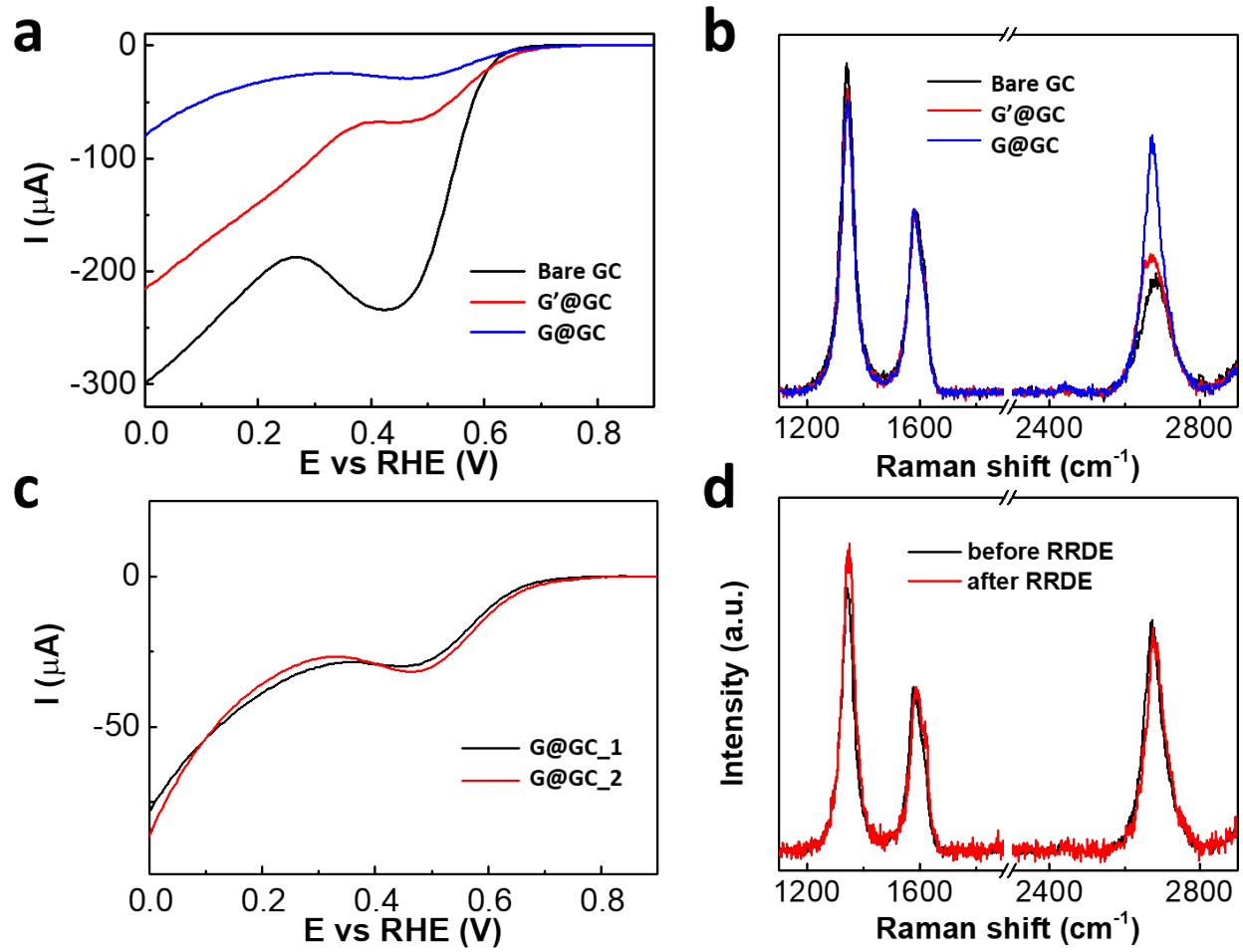

Figure S6. ORR activity and Raman spectroscopy of G@GC vs G'@GC for RRDE experiment. a) LSV curves of bare GC, G'@GC and G@GC at600 rpm. b) Raman spectra of bare GC, G'@GC and G@GC supported by GC. c) LSV polarization curves of two samples of G@GC supported by the same GC disk electrode at $800 \mathrm{rpm}$. d) Raman spectra of the bilayer graphene on the GC disk before and after RRDE experiment. All the ORR experiment were performed in $0.1 \mathrm{M}$ sodium hydroxide solution saturated with $\mathrm{O}_{2}$.

\subsection{Reproducibility and reliability of G@GC for RRDE experiment}


Raman spectroscopy and repeated ORR tests were performed to confirm the reliability and reproducibility of G@GC. The Raman spectra of G'@GC and G@GC both show increased peak intensity of 2D peak compared to that of the bare GC (Figure S6b). Especially the peak intensity ratio of $\mathrm{I}(2 \mathrm{D}) / \mathrm{I}(\mathrm{G})$, an indicator of graphene layer number ${ }^{5}$, is as high as 1.4 for $\mathrm{G} @ \mathrm{GC}$ while below 1.0 for both G'@GC (0.75) and the GC (0.65). Therefore, we can conclude that G@GC behaves more independently than G'@GC supported on GC. In addition, the well-overlapped LSV curves at 800 rpm obtained from two different G@GC samples in Figure S6c show a good reproducibility. Raman characterization of $\mathrm{G} @ \mathrm{GC}$ before and after RRDE experiments (Figure S6d) confirms the stability of bilayer graphene. As a result, bilayer graphene is used as a pristine surface on RRDE for further doping treatments and ORR catalysis.

\subsection{Koutechy-Levich analysis}

At different rotation rates, the limiting current for oxygen reduction behaves according to the KouteckyLevich equation ${ }^{6}$ :

$\frac{1}{I}=\frac{1}{I_{\mathrm{K}}}+\frac{1}{I_{\mathrm{L}}}$

where $I$ is the observed current, $I_{\mathrm{K}}$ is the kinetic current that can be observed when the mass transport rate to the electrode is much greater than the reaction rate, $I_{\mathrm{L}}$ is the diffusion limited current that can be obtained when the reaction rates is much larger than the mass transport rate. The diffusion-limited current can be described by the Levich equation:

$I_{\mathrm{L}}=0.62 n F A D_{O}^{2 / 3} C_{O} v^{-1 / 6} \omega^{1 / 2}=B n A \omega^{1 / 2}$

where $n$ is the electron transfer number, $F$ is the Faraday constant $\left(\mathrm{C} \mathrm{mol}^{-1}\right), A$ is the electrode area $\left(\mathrm{cm}^{2}\right.$ ), $D_{0}$ is the diffusion coefficient of $\mathrm{O}_{2}\left(\mathrm{~cm}^{2} \mathrm{~s}^{-1}\right), C_{0}$ is the concentration of $\mathrm{O}_{2}$ in the electrolyte, $v$ is the kinematic viscosity $\left(\mathrm{cm}^{2} \mathrm{~s}^{-1}\right)$ and $\omega$ the rotation rate $\left(\mathrm{rad} \mathrm{s}^{-1}\right)$. The equation can be simplified with the Levich constant defined as $B$. By performing rotating ring disk electrode (RRDE) experiments for ORR with a platinum disk electrode (Figure S8), $B$ can be calculated using the slope of the Koutecky-Levich plot (as platinum is known to be a 4-electron dioxygen reduction catalyst):

slope $=\frac{1}{B n A}$

The Koutecky-Levich plots in Figure 3g and the K-L intercepts in Figure 3i compare the activities for different graphene samples using the intersection at the axis of $1 / I_{\text {disk }}$, which corresponds to the kinetics current $\left(I_{\mathrm{K}}\right)$. A higher $I_{\mathrm{K}}$, a direct indicator of a higher catalytic activity, will be reflected by a value of the $1 / I_{\text {disk }}$ intersection closer to zero. 
The collection efficiency of rotating disk ring electrode (RRDE) was calculated based on the reversible redox reaction of potassium ferricyanide. In $0.1 \mathrm{M}$ sodium perchlorate purged with argon, $1 \mathrm{mM}$ potassium ferricyanide (III) was reduced at the glassy carbon disk to Fe(II) which can be re-oxidized at the platinum ring. Of note, the reversible hydrogen electrode (RHE) as the reference electrode in the Luggin capillary was only in contact with $0.1 \mathrm{M}$ sodium perchlorate. As illustrated in Figure S8, the redox currents were recorded at both the disk and ring at different rotation rates ranging from 400 to $1000 \mathrm{rpm}$. Based on the currents, the collection efficiency ratio of the ring was determined as $22.5 \%$.

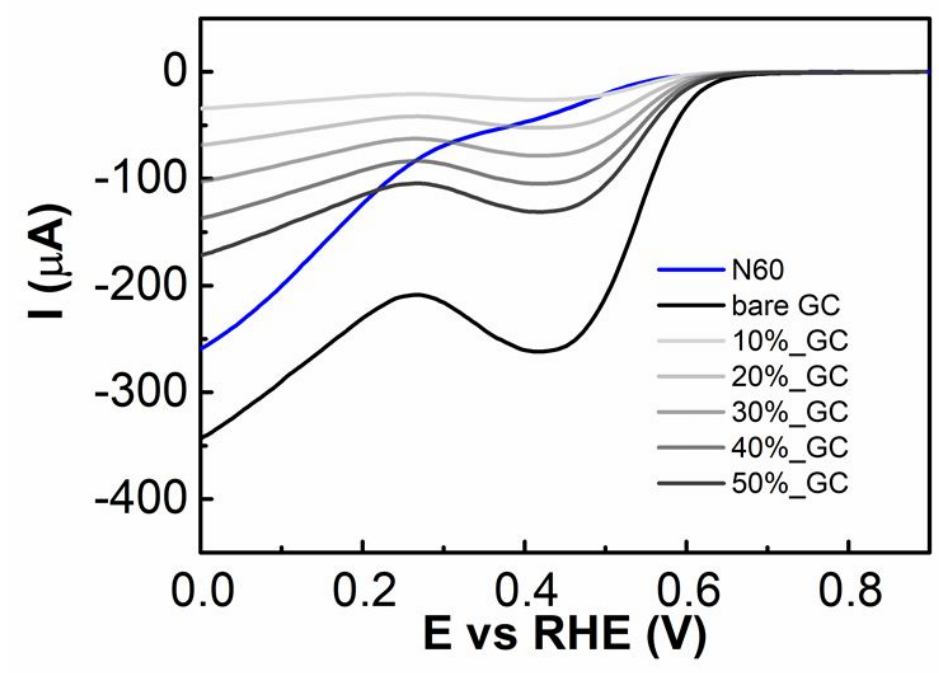

Figure S7. LSV curves for 60 s nitrogenated G@GC (denoted as N60) and for the GC disk with full (bare GC) or partial exposure $(10 \%$ to $50 \%)$ in terms of the electrode area. The electrolyte solution is $0.1 \mathrm{M}$ sodium hydroxide saturated with $\mathrm{O}_{2}$.
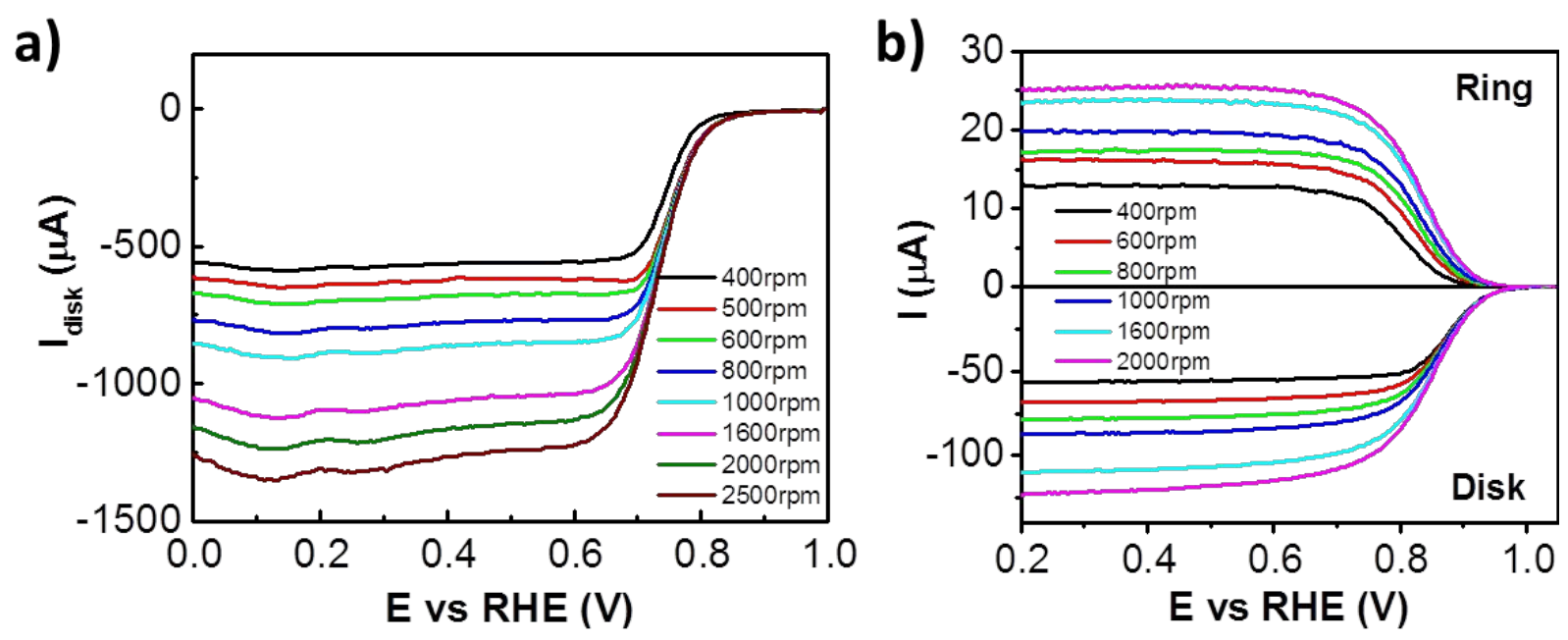

Figure S8. Levich constant and collection efficiency. a) ORR polarization curves at different rotation rates on a platinum disk electrode in $0.1 \mathrm{M} \mathrm{NaOH}$ solution saturated with $\mathrm{O}_{2}$. b) Currents on the GC 
disk and platinum ring electrodes for $1 \mathrm{mM} \mathrm{K}_{3}\left[\mathrm{Fe}(\mathrm{CN})_{6}\right]$ in $0.1 \mathrm{M} \mathrm{NaClO}_{4}$ purged with argon at different rotation speeds.

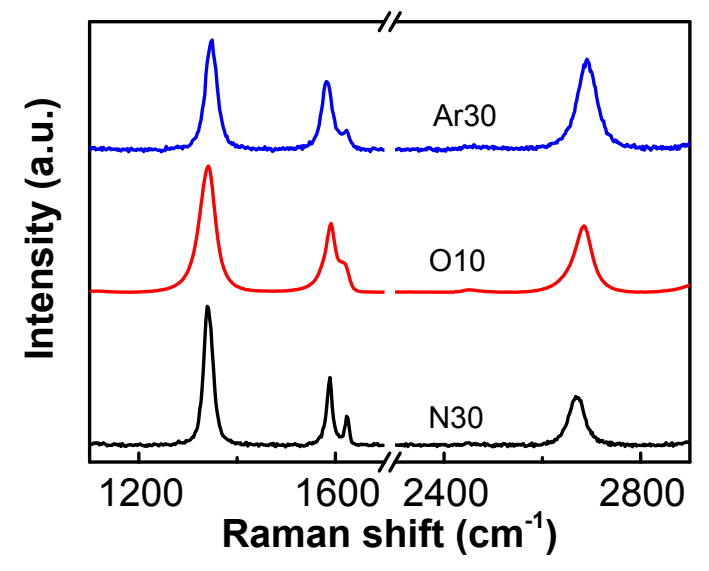

Figure S9. Raman spectra for N30, O10 and Ar30 with comparable defect densities.
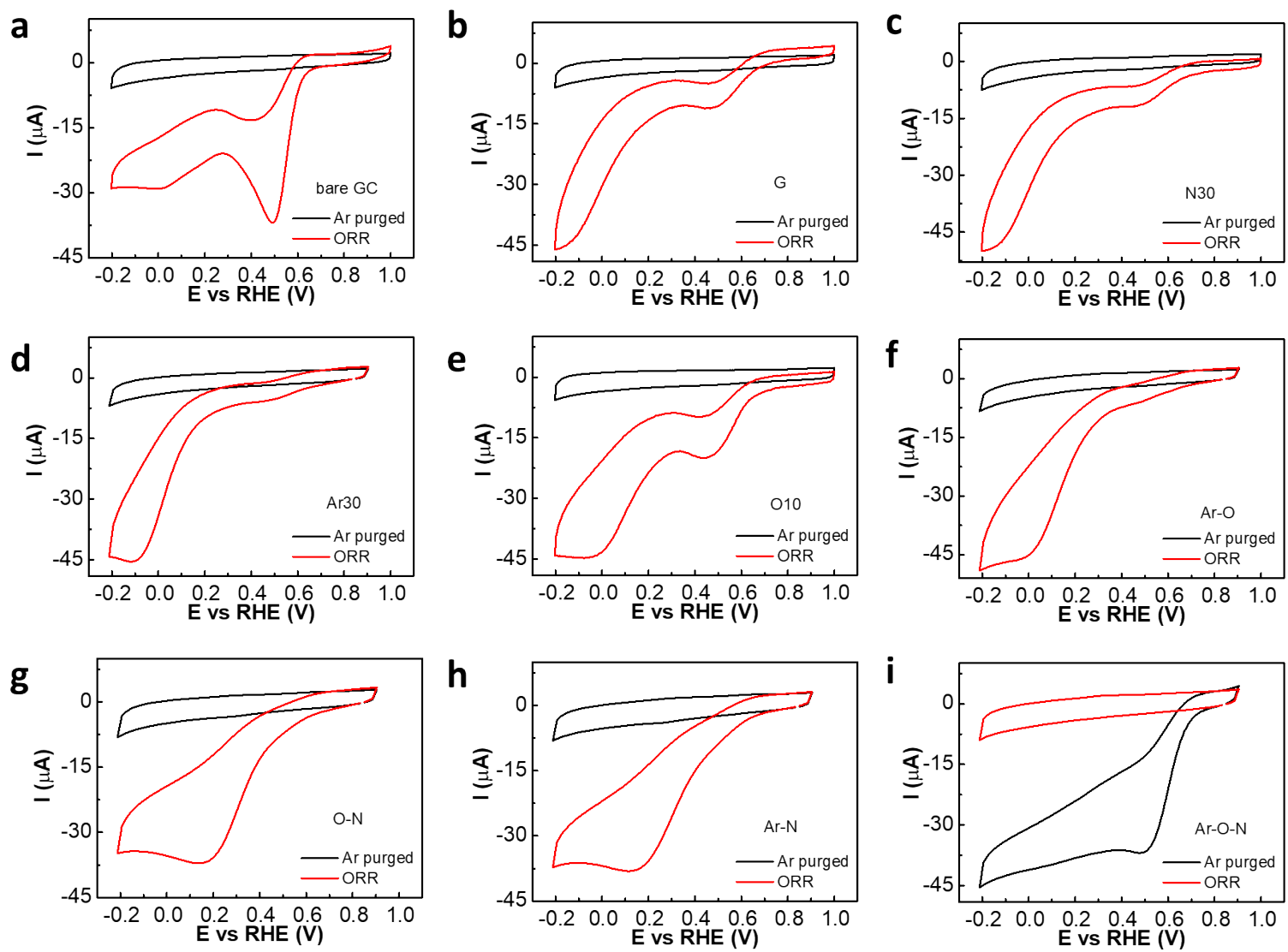

Figure S10. CV curves of bare GC and G@GC samples before and after doping treatment in $0.1 \mathrm{M}$ $\mathrm{NaOH}$ solution purged with argon and oxygen. a) bare GC, b) G, c) N30, d) Ar30, e) O10, f) Ar-O, g) $\mathrm{O}-\mathrm{N}, \mathrm{h})$ Ar-N and i) Ar-O-N. 

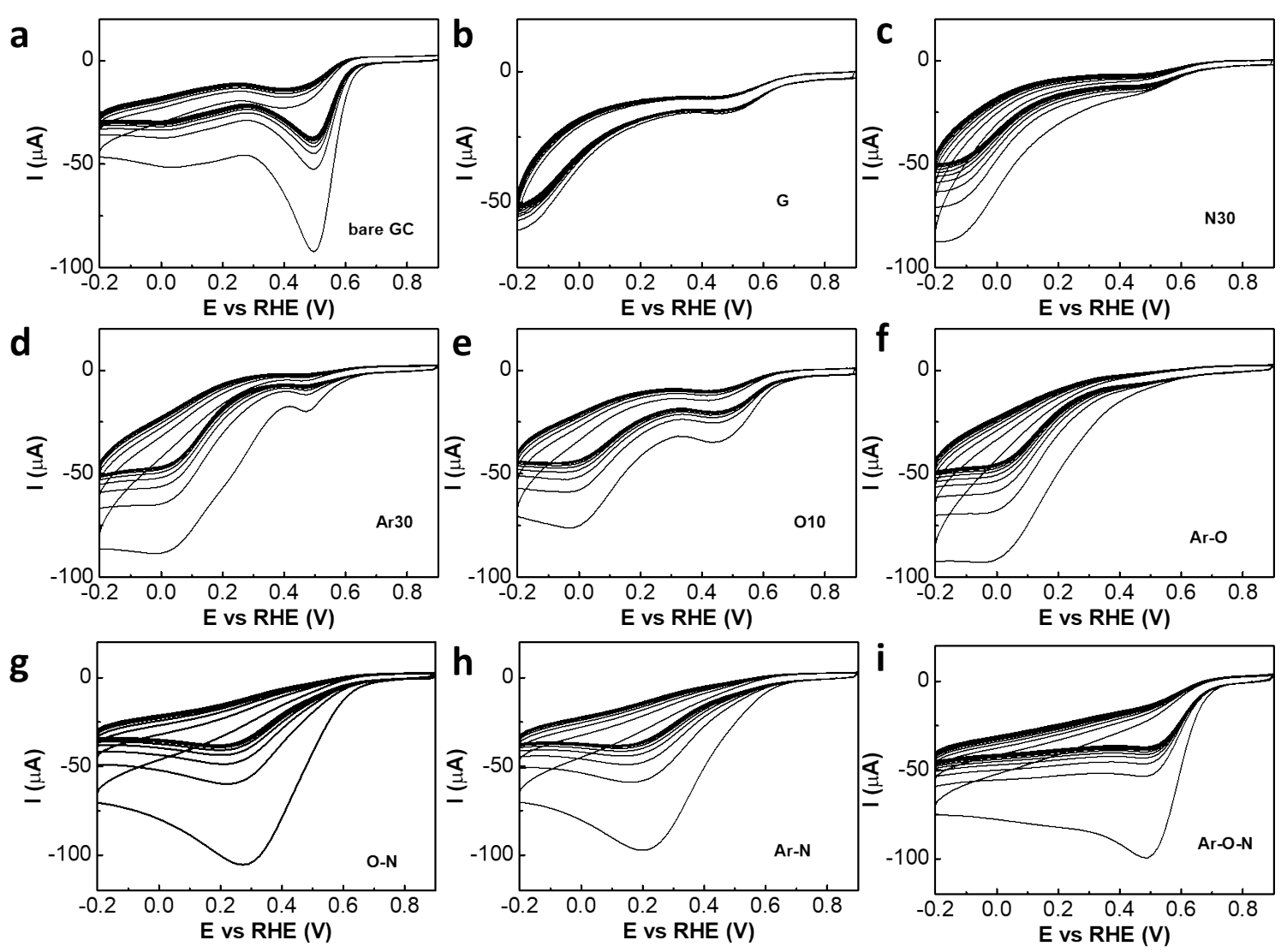

Figure S11. CV scans of bare GC and G@GC samples in $0.1 \mathrm{M} \mathrm{NaOH}$ solution purged with oxygen to obtain stable current signals as shown in Figure S10. a) bare GC, b) G, c) N30, d) Ar30, e) O10, f) Ar$\mathrm{O}, \mathrm{g}) \mathrm{O}-\mathrm{N}, \mathrm{h}$ ) Ar-N and i) Ar-O-N. 
a

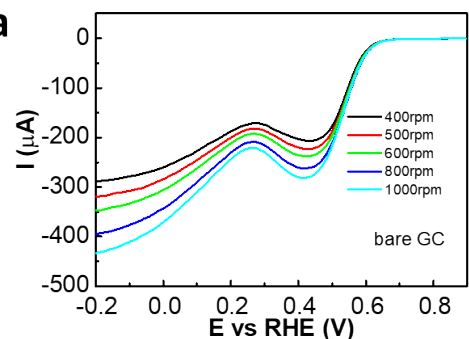

d
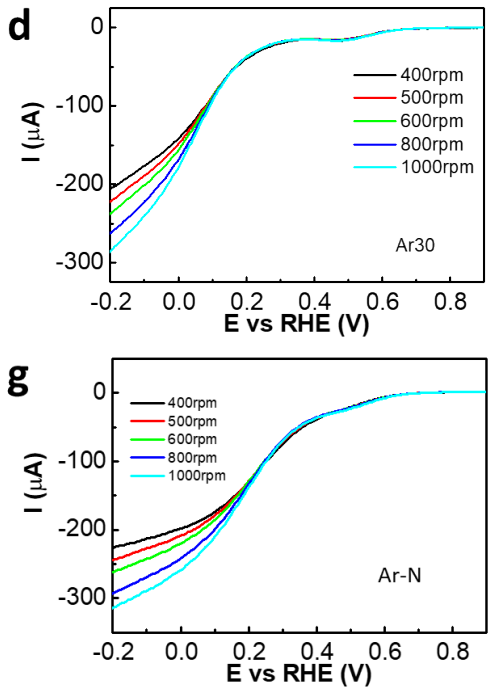
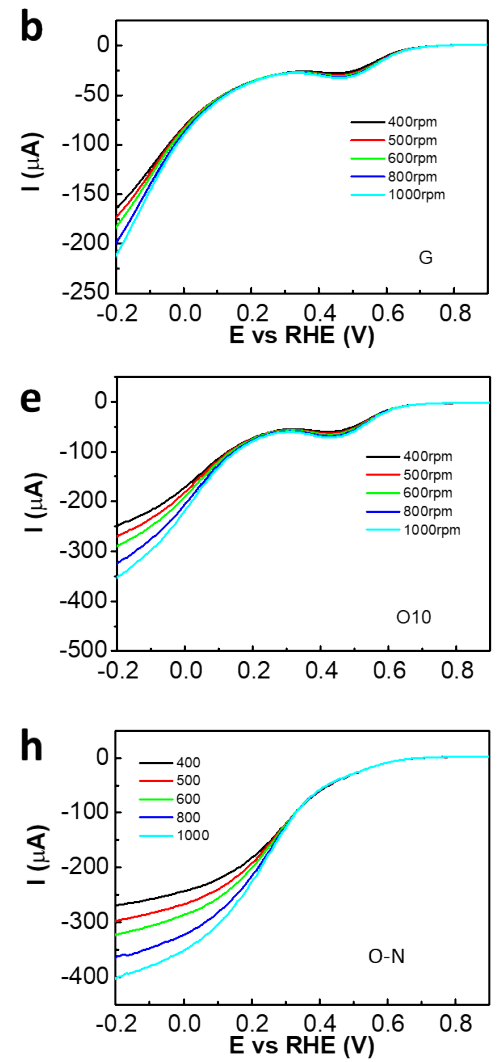
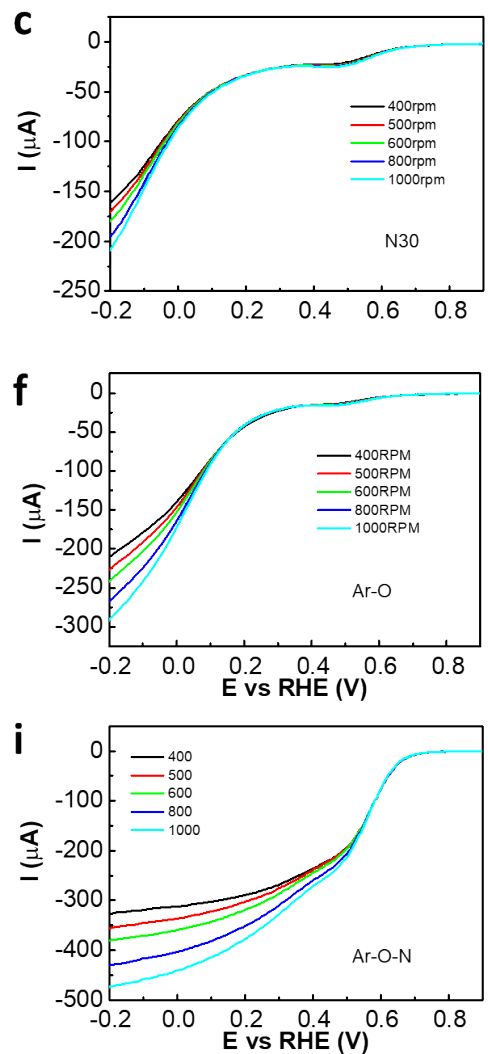

Figure S12. LSV curves at rotation rates ranging from 400 to $1000 \mathrm{rpm}$ for bare GC and different graphene samples supported on GC: a) bare GC, b) G, c) N30, d) Ar30, e) O10, f) Ar-O, g) O-N, h) $\mathrm{Ar}-\mathrm{N}$ and i) Ar-O-N. The increasing currents at Ar-O-N with the rotation speed ranging from 400 to $1000 \mathrm{rpm}$ indicate that a normal diffusional-limited current is reached at Ar-O-N, which is in contrast with the diffusion condition for other samples.

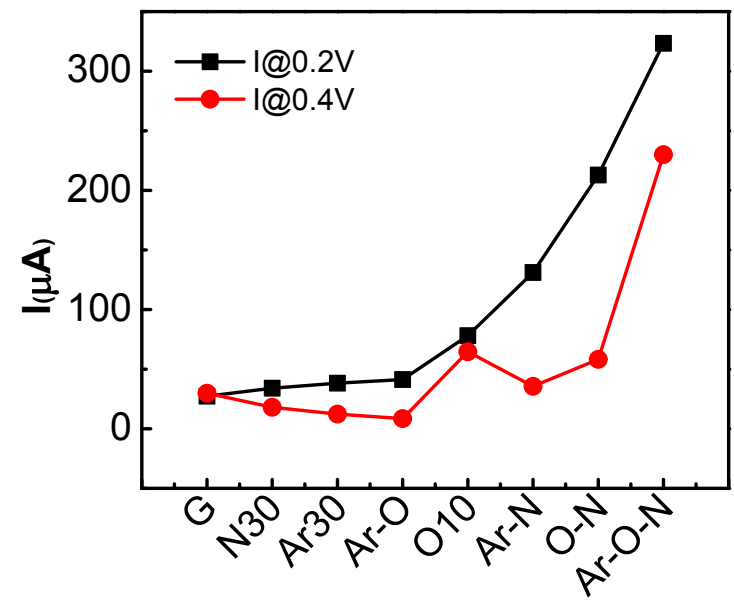

Figure S13. Comparison of ORR activities at potentials of 0.2 and $0.4 \mathrm{~V}$ vs. RHE for different graphene samples. 
a
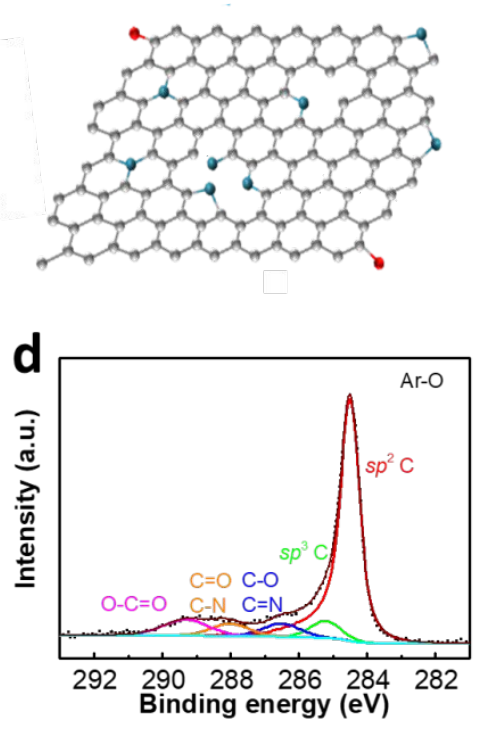

b
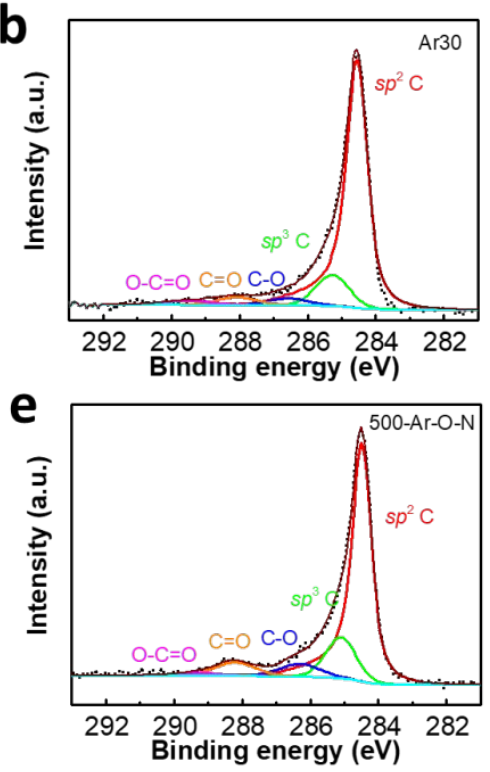
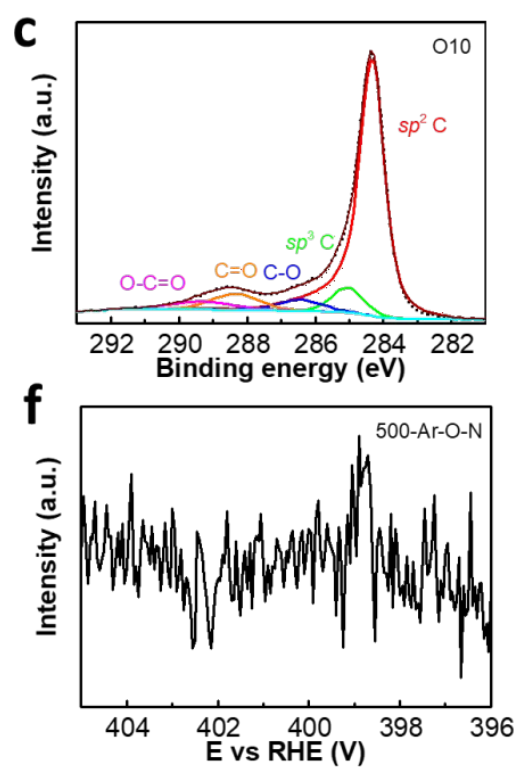

Figure S14. a) A scheme of graphene lattice doped with oxygen dopants (red) as well as vacancy defects accompanying nitrogen dopants (blue). C $1 s$ core level spectra for b) Ar30, c) O10, d) Ar-O, e) 500-ArO-N. N $1 s$ core spectra for f) 500-Ar-O-N.

Table S2 XPS analysis results for different doped graphene samples*

\begin{tabular}{|c|c|c|c|c|c|c|c|c|c|c|}
\hline \multirow{3}{*}{ samples } & \multicolumn{10}{|c|}{ Concentrations of species (\%) } \\
\hline & $s p^{2} \mathrm{C}$ & $s p^{3} \mathrm{C}$ & \multirow{2}{*}{\multicolumn{2}{|c|}{$\begin{array}{c}\mathrm{C}-\mathrm{O} / \mathrm{C}=\mathrm{N} \\
286.4 \mathrm{eV}\end{array}$}} & \multirow{2}{*}{\multicolumn{2}{|c|}{$\begin{array}{l}\mathrm{C}=\mathrm{O} / \mathrm{C}-\mathrm{N} \\
288.0 \mathrm{eV}\end{array}$}} & \multirow{2}{*}{$\begin{array}{c}\mathrm{O}-\mathrm{C}=\mathrm{O} \\
289.5 \mathrm{eV}\end{array}$} & \multirow{2}{*}{$\begin{array}{c}\text { Pyrid-N } \\
398.9 \\
\text { eV }\end{array}$} & \multirow{2}{*}{$\begin{array}{c}\text { Pyrro-N } \\
399.9 \\
\mathrm{eV}\end{array}$} & \multirow{2}{*}{$\begin{array}{c}\text { Quat-N } \\
401.1 \\
\mathrm{eV}\end{array}$} \\
\hline & $284.6 \mathrm{eV}$ & $285.0 \mathrm{eV}$ & & & & & & & & \\
\hline G & 65.6 & 24.5 & 6.1 & 0 & 1.9 & 0 & 1.9 & - & - & - \\
\hline N30 & 77.1 & 12.7 & 4.2 & 0.2 & 1.7 & 1.5 & 1.7 & 0.2 & 1.5 & - \\
\hline N60 & 61.3 & 21.3 & 7.8 & 0.9 & 1.3 & 2.0 & 5.3 & 0.5 & 2.0 & 0.4 \\
\hline Ar30 & 78.8 & 11.9 & 3.2 & & 3.6 & & 2.5 & & & \\
\hline Ar-O & 73.4 & 6.2 & 6.0 & & 5.7 & & 8.7 & - & - & - \\
\hline $\mathrm{O} 10$ & 67.6 & 7.2 & 8.3 & & 14.3 & & 2.7 & & & - \\
\hline Ar-N & 64.2 & 17.8 & 4.1 & 1.5 & 2.7 & 2.9 & 2.3 & 0.9 & 2.9 & 0.6 \\
\hline $\mathrm{O}-\mathrm{N}$ & 66.6 & 13.2 & 4.1 & 1.5 & 1.3 & 2.9 & 6.1 & 1.1 & 2.9 & 0.4 \\
\hline Ar-O-N & 69.1 & 9.4 & 4.7 & 1.0 & 3.2 & 3.5 & 4.7 & 0.7 & 3.5 & 0.3 \\
\hline 500-Ar-O-N & 71.1 & 14.9 & 6.1 & & 6.4 & & 1.4 & & & \\
\hline
\end{tabular}

* G, N30 and N60 are referred to be pristine graphene, $30 \mathrm{NH}_{3}$ and $60 \mathrm{~s} \mathrm{NH}_{3}$ treated graphene in Figure

S4. XPS characterizations were performed on graphene supported by copper foil. PMMA coating and removal procedure were introduced to simulate the transfer process and the resultant polymer residues effect on chemical compositions. 

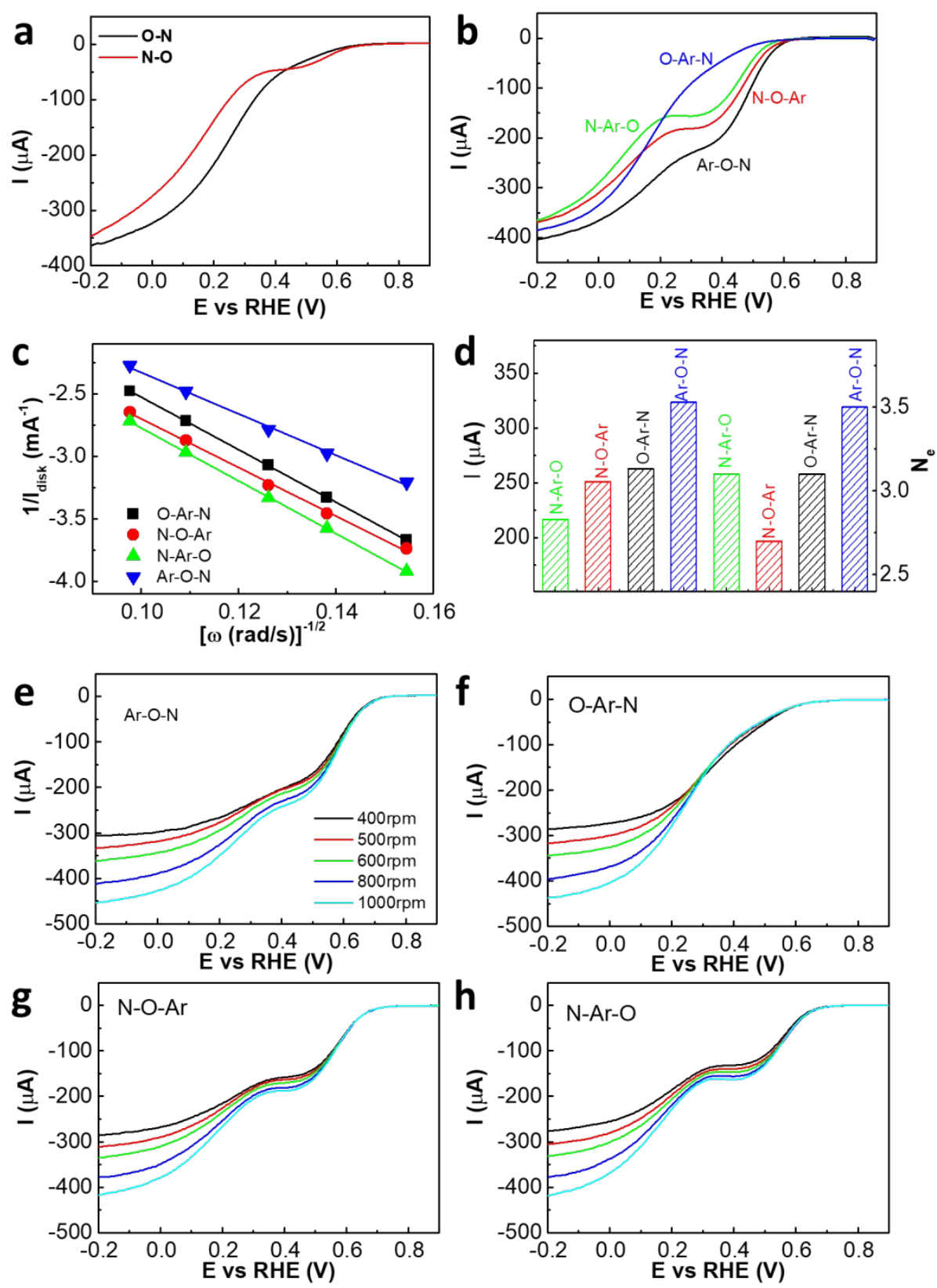

Figure S15. ORR activities comparison between different co-doped graphene. a) LSV polarization curves of O-N and N-O. b) LSV polarization curves of Ar-O-N, O-Ar-N versus N-O-Ar, N-Ar-O. c) K-L plots. d) ORR activities (at $0.1 \mathrm{~V}$ vs RHE) and electron transfer number $\mathrm{N}_{\mathrm{e}}$. e) ORR polarization curves of Ar-O-N at different rotation rates. f) ORR polarization curves of O-Ar-N at different rotation rates. g) ORR polarization curves of $\mathrm{N}-\mathrm{O}-\mathrm{Ar}$ at different rotation rates. $\mathrm{h}$ ) ORR polarization curves of $\mathrm{N}-\mathrm{Ar}-\mathrm{O}$ at different rotation rates. All the ORR experiments were performed in $0.1 \mathrm{M} \mathrm{NaOH}$ solutions saturated with $\mathrm{O}_{2}$ at a rotation speed of $800 \mathrm{rpm}$ (scan rate of $100 \mathrm{mV} / \mathrm{s}$ ).

\section{References:}

1 Lu, Y.-F. et al. Nitrogen-doped graphene sheets grown by chemical vapor deposition: synthesis and influence of nitrogen impurities on carrier transport. ACS Nano 7, 6522-6532 (2013).

2 Jin, Z., Yao, J., Kittrell, C. \& Tour, J. M. Large-scale growth and characterizations of nitrogendoped monolayer graphene sheets. ACS Nano 5, $4112-4117$ (2011).

3 Schiros, T. et al. Connecting dopant bond type with electronic structure in N-doped graphene. Nano Lett. 12, 4025-4031 (2012). 
$4 \mathrm{Li}$, J. et al. Electron-hole symmetry breaking in charge transport in nitrogen-doped graphene. ACS Nano 11, 4641-4650 (2017).

5 Hao, Y. et al. Probing layer number and stacking order of few-layer graphene by Raman spectroscopy. Small 6, 195-200 (2010).

6 Bard, A. J., Faulkner, L. R., Leddy, J. \& Zoski, C. G. Electrochemical methods: fundamentals and applications. Vol. 2 (wiley New York, 1980).

7 Yang, H. B. et al. Identification of catalytic sites for oxygen reduction and oxygen evolution in N-doped graphene materials: Development of highly efficient metal-free bifunctional electrocatalyst. Sci. Adv. 2, e1501122 (2016).

8 Hall, S. B., Khudaish, E. A. \& Hart, A. L. Electrochemical oxidation of hydrogen peroxide at platinum electrodes. Part IV: phosphate buffer dependence. Electrochim. Acta 44, 4573-4582 (1999).

9 Zhou, R., Zheng, Y., Jaroniec, M. \& Qiao, S.-Z. Determination of the electron transfer number for the oxygen reduction reaction: from theory to experiment. ACS Catal. 6, 4720-4728 (2016).

10 Hall, S. B., Khudaish, E. A. \& Hart, A. L. Electrochemical oxidation of hydrogen peroxide at platinum electrodes. Part 1. An adsorption-controlled mechanism. Electrochim. Acta 43, 579588 (1998). 